\title{
RE-1 Silencer of Transcription/Neural Restrictive Silencer Factor Modulates Ectodermal Patterning during Xenopus Development
}

\author{
Patricio Olguín, ${ }^{1}$ Pablo Oteíza, ${ }^{1}$ Eduardo Gamboa, ${ }^{1}$ José Luis Gómez-Skármeta, ${ }^{2}$ and Manuel Kukuljan ${ }^{1}$ \\ ${ }^{1}$ Centro de Neurociencias Integradas, Iniciativa Científica Milenio, and Programa de Fisiología y Biofísica, Instituto de Ciencias Biomedicas, Facultad de \\ Medicina, Universidad de Chile, 838-0453 Independencia, Chile, and ${ }^{2}$ Centro Andaluz de Biología del Desarrollo, Consejo Superior de Investigaciones \\ Científicas/Universidad Pablo de Olavide, 41013 Sevilla, Spain
}

RE-1 silencer of transcription/neural restrictive silencer factor (REST/NRSF), a transcriptional repressor, binds to the RE-1 element present in many vertebrate genes. In vitro studies indicate that REST/NRSF plays important roles in several stages of neural development. However, a full understanding of its physiological function requires in vivo approaches. We find that impairment of REST/NRSF function in Xenopus embryos leads to the perturbation of neural tube, cranial ganglia, and eye development. The origin of these defects is the abnormal patterning of the ectoderm during gastrulation. Interference of REST/NRSF function during the late blastula stage leads to an expansion of the neural plate, concomitant with a decrease of the expression of epidermal keratin and neural crest markers. Furthermore, neurogenesis proceeds abnormally, with loss of the expression of proneural, neurogenic, and neuronal genes. The interference of REST/ NRSF mimics several features associated with a decreased bone morphogenetic protein (BMP) function and counteracts some effects of BMP4 misexpression. Our results indicate that REST/NRSF function is required in vivo for the acquisition of specific ectodermal cell fates.

Key words: neurogenesis; neural induction; differentiation; transcription factor; ectoderm; neural precursor

\section{Introduction}

The development of the nervous system relies on the regulation of gene expression that commands the passage of a population of undifferentiated epithelial cells into distinct cell types. This process results from the activity of many transcriptional regulators, expressed as the result of cell-autonomous and intercellular interactions. The RE-1 silencer of transcription/neural restrictive silencer factor (REST/NRSF) functions as a scaffold that recruits chromatin remodeling complexes, as well as RNA polymerase phosphatases to the genes containing RE-1 sequences and thus modulates transcription (Chong et al., 1995; Schoenherr and Anderson, 1995; Andrés et al., 1999; Huang et al., 1999; Grimes et al., 2000; Ballas et al., 2001; Lunyak et al., 2002; Roopra et al., 2004; Yeo et al., 2005).

RE-1 sites were first characterized within the context of neuronal genes, such as ion channels, neurotransmitter receptors, and cytoskeletal proteins (Kraner et al., 1992; Mori et al., 1992). This fact, together with the expression pattern of the

Received Aug. 10, 2005; revised Jan. 20, 2006; accepted Jan. 24, 2006.

This work was supported by Iniciativa Científica Milenio (Chile) Grant ICM P-01-007-F (M.K.) and Spanish Ministry of Education and Science Grant BFU2004-00310 (J.L.G-S.). P.0. was supported by a Comisión Nacional de Investigación Científica y Tecnológica (Chile) fellowship and Predoctoral Grant AT 403023. We are grateful to Drs. A. Ribera, A. Glavic, and R. Armisén for critical reading of this manuscript and Dr. G. Mandel for her support during the course of the work.

Correspondence should be addressed to Manuel Kukuljan and Patricio Olguín, Programa de Fisiología y Biofísica, Instituto de Ciencias Biomedicas, Facultad de Medicina, Universidad de Chile, Avenida Independencia 1027, 8380453 Independencia, Chile. E-mails: kukuljan@neuro.med.uchile.cl and polguin@med.uchile.cl.

DOI:10.1523/JNEUROSCI.5037-05.2006

Copyright $\odot 2006$ Society for Neuroscience $\quad$ 0270-6474/06/262820-10\$15.00/0
mRNA encoding REST/NRSF and an extensive molecular characterization of its function, led to the view of REST/NRSF as a factor that silences neuronal genes in non-neuronal cell types and immature neuronal precursors. Nevertheless, RE-1, as well as other putative REST/NRSF binding sites, is found in many genes that do not encode neuron-specific proteins (Schoenherr et al., 1996; Lunyak et al., 2002; Bruce et al., 2004). These observations support the view that REST/NRSF participates in the regulation of many cellular processes in a context-dependent manner.

REST/NRSF plays distinct roles in the transit of neural stem cells from their pluripotential stage to differentiated neurons (Ballas et al., 2005) and has also been identified as a tumor suppressor gene that is deleted in human neoplasias (Westbrook et al., 2005). Additionally, REST/NRSF function also appears to be required for normal cardiac development (Kuwahara et al., 2003). Homozygous deletion of the REST/NRSF gene is lethal for mice at approximately embryonic day 10. Examination of these embryos reveals derepression of some neuronal genes, manifested as ectopic expression (Chen et al., 1998). Conversely, gain of function of REST/NRSF in developing chick spinal neurons results in repression of the expression of some neuronal genes and defects in axon navigation, without evident perturbation of neurogenesis (Paquette et al., 2000).

Our previous study of REST/NRSF function in vivo, using the Xenopus laevis embryo model (XREST/NRSF), showed that interference with its function does not lead to early lethality. Furthermore, REST/NRSF interference results in repres- 
sion of neuronal gene expression at neurula stages (Armisén et al., 2002). This view contrasted with the body of knowledge that emerged from molecular studies. Here, we trace the origins of the defects associated with the interference of XREST/ NRSF function to the acquisition of the cell fates of the ectoderm, using an inducible dominant-negative (dn) XREST/ NRSF form and a morpholino-modified antisense oligonucleotide in Xenopus embryos (MoREST). Our findings are consistent with the need of XREST/NRSF function for the appropriate patterning of the ectoderm, at least in part through mechanisms that involve the modification of bone morphogenetic protein (BMP) signaling.

\section{Materials and Methods}

Isolation of XREST/NRSF cDNA and plasmid constructions. Total RNA was purified from early gastrula embryos using Trizol (Invitrogen, Carlsbad, CA), and cDNA was synthesized using SuperScript II (Invitrogen) and a specific primer designed on the basis of expressed sequence tag (EST) clone XL066i17, which encodes the predicted C terminus and 3' untranslated region of XREST/NRSF. We amplified the XREST/NRSF coding region by PCR using Expand Long Template PCR System (Roche Molecular Biochemicals, Basel, Switzerland). Forward primer CGCTCGAGATGGCCACTCAAATGGTCAAC was designed to match the $5^{\prime}$ end of a partial XREST/NRSF clone (GenBank accession number AF096301) and reverse primer GCTCTAGATTATCTATGTCTTTTGCTGCTTTTTTAAG was based on the EST clone XL066i17. The PCR product was cloned into the pGEMT-Easy (Promega, Madison, WI), excised with $\mathrm{XhoI}$ and $\mathrm{XbaI}$ (in bold in the primer sequences), cloned into pCS2+NLS/MT (Turner and Weintraub, 1994), and sequenced. The DNA binding domain of XREST/NRSF was amplified with the primers GCGAATTCTAATACACTTGAGGTGGAGG and CGCTCGAGTTTTACTTTGGAAACATCCATTGTG, and the PCR product was digested with EcoRI and XhoI and ligated with the fragment encoding the human glucocorticoid receptor hormone binding domain, obtained from digestion of the fragment cloned in pBluescript KS (Gómez-Skármeta et al., 2001) with XhoI and XbaI, and the pCS2 + MT plasmid digested with EcoRI and XbaI.

Cloning of ZREST/NRSF. Total RNA was purified from $24 \mathrm{~h}$ postfertilization zebrafish embryos using Trizol (Invitrogen), and cDNA was synthesized using SuperScript II (Invitrogen) with a specific reverse primer designed on the basis of the predicted zebrafish ZREST/NRSF gene (www.ensembl.org). This sequence was obtained by a sequence similarity search using the TBLASTX tool in the annotated genomic sequence of zebrafish. We amplified ZREST/NRSF coding region by PCR using Expand High Fidelity PCR System (Roche Molecular Biochemicals). Forward primer CGCTCGAGCCGGTGTTTCCCACTGCC and reverse primer GCTTCTAGAGCTGCCGCCCCTTCTAG were designed to match the start and the end of the putative coding region, as suggested by the comparison of the predicted proteins with hREST/ NRSF, XREST/NRSF, and rREST/NRSF and the Genescan analysis available with the genomic database. The PCR product was cloned into pCR4TOPO (Invitrogen), excised with Xho and Xba (in bold in the primer sequences), sequenced, and cloned into pCS2+NLS/MT (Turner and Weintraub, 1994).

Embryo manipulation and microinjection. Eggs were obtained from adult $X$. laevis frogs and fertilized in vitro using standard procedures (Sive et al., 2000). Embryos were maintained at $18^{\circ} \mathrm{C}$ in $0.1 \times$ modified Barth's saline (MBS) and exposed to dexamethasone $(10 \mu \mathrm{M})$ at the indicated stages. Staging was done according to Niewkoop and Faber (1967). Ectodermal explants, or "animal caps" (ACs), were dissected from stage 9 embryos using eyebrow knives in $1 \times$ MBS, cultured in $0.5 \times$ MBS, and exposed to dexamethasone at the equivalent stages 9.5, assessed from sibling embryos. Synthetic RNAs were microinjected into the animal pole of one blastomere at the two-cell stage. For AC experiments, RNA was injected in the four animal blastomeres at the 4- to 8-cell stage. RNAs were synthesized in vitro with SP6 RNA polymerase in the presence of cap analog (Message Machine; Ambion, Austin, TX) using each linearized plasmid as template: dnXREST, XREST/NRSF, and BMP4 (Suzuki et al.,
1997). $\beta$-Galactosidase RNA was injected as lineage tracer for experiments that would be processed by in situ hybridization (ISH), whereas green fluorescent protein (GFP) RNA was injected to verify the localization of the injected material in embryos used for preparation of ACs. Injection of MoXREST was as described previously (Armisén et al., 2002). As a control for the specificity of the MoXREST, a control morpholino (TTTCAGACGGACCACTGTCAGTGCG) was injected. Primers for XREST1 were XREST1F (GCTGTCAGATGTAATTGCGC) and XREST1R (TTGTGTAAGTCGGCTGCTCC).

$I S H$. Injected embryos and caps were prefixed in MEMFA [100 mM 3-( $N$-morpholino)-propanesulfonic acid, pH 7.4, 2 mм EGTA, $1 \mathrm{~mm}$ $\mathrm{MgSO}_{4}$, and 3.7\% formaldehyde] for $45 \mathrm{~min}$, and the activity of the $\beta$-galactosidase lineage tracer was assessed using 5-bromo-4-chloro-3indolyl- $\beta$-D-galactopyranoside as substrate. Stained embryos were fixed in MEMFA for 1 additional hour and processed for whole-mount in situ hybridization with digoxigenin-labeled probes (Roche Molecular Biochemicals) as described previously (Harland, 1991). Antisense riboprobes were prepared for X-ngnr-1 (Ma et al., 1996), X-Delta-1, Notch-1, and N-tubulin (Chitnis et al., 1995), Nav1.2 and SCG10 (Armisén et al., 2002), Zic2 (Brewster et al., 1998), chordin (Sasai et al., 1994), SoxD (Mizuseki et al., 1998a), Sox2 (Mizuseki et al., 1998b), keratin (K81A) (Jonas et al., 1985), Slug (Mayor et al., 1995), and msx-1 (Suzuki et al., 1997). Hes-1 (EST clone Mochii XL036f10; http://Xenopus.nibb.ac.jp) was digested with EcoRI and in vitro transcribed with T7 RNA polymerase (Ambion).

Semiquantitative PCR analysis. Total RNA was isolated from $15 \mathrm{ACs}$ at stage 10.5, using Trizol reagent (Invitrogen). cDNAs were synthesized using Superscript II reverse transcriptase (Invitrogen) and oligo-dT primer. Semiquantitative PCR was conducted as described by Gawantka et al. (1995). The primers were as follows: Msx-1F, GCTAAAAATGGCTGCTAA; Msx-1R, AGGTGGGCTGTGTAAAGT; Vent2F, CATCATCATCCCCTGGAG; Vent2R, TAGAGTTGGATCGACTCGT; ODCF, GTCAATGATGGGTG TATGGATC; and ODCR, TCCATTCCGCTCTCCTGAGCAC.

\section{Results}

\section{REST/NRSF is widely expressed in the ectoderm during early Xenopus development}

The cDNA encoding $X$. laevis REST/NRSF (XREST/NRSF) predicts a protein with high sequence identity in domains relevant for DNA binding and interaction with corepressors in human, rat, mouse, and the predicted zebrafish REST/NRSF proteins (supplemental Fig. S1, available at www.jneurosci.org as supplemental material). These domains comprise eight zinc fingers that bind to DNA, a ninth zinc finger that interacts with the REST/ NRSF corepressor CoREST (Andrés et al., 1999), and a short stretch in the N-terminal region (amino acids 32-122 of hREST) thought to bind Sin3 (Grimes et al., 2000). This observation suggests a conserved function for REST/NRSF among vertebrates, in terms of recruiting chromatin-remodeling complexes to RE-1 sites. Nevertheless, it is of interest to notice the low conservation, in terms of amino acid composition and length of the intervening domains; these may support still uncharacterized functions in the respective species.

XREST/NRSF transcripts are widely distributed during Xenopus embryonic development, both before and after the beginning of zygotic transcription (Armisén et al., 2002). At early gastrula stages, XREST/NRSF mRNA is detectable throughout the ectoderm and slightly in the dorsal marginal zone. By the onset of neurulation (stage 13 onward), the expression of XREST/NRSF declines, although a more marked expression is noticed at the borders of the prospective neural plate. At the neural tube stage, $X R E S T / N R S F$ is expressed in the presomitic mesoderm and in the limit of the cephalic neural crest (supplemental Fig. S2, available at www.jneurosci.org as supplemental material). 

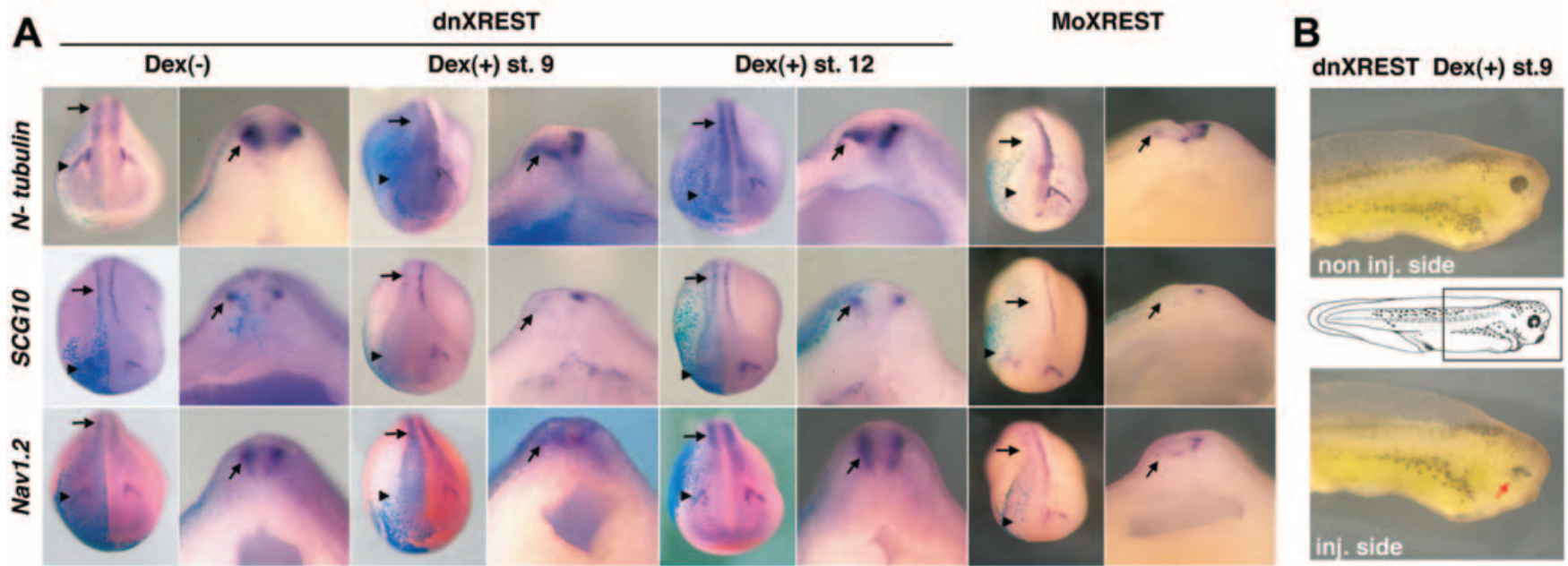

Figure 1. XREST/NRSF is required for morphogenesis and neuronal gene expression during early stages of neurogenesis. $\boldsymbol{A}$, Anterodorsal views and transversal sections of embryos fixed at late neurula, injected with $500 \mathrm{pg}$ of dnXREST or 5 pmol of MoXREST (indicated on top) in one cell at the 2-cell stage; the injected side in all figures is to the left. Embry0s exposed to dexamethasone at late blastula [Dex(+) st. 9] and embryos injected with MoXREST exhibit an apparent loss of expression of neuronal genes in neural tube (arrows) and in the trigeminal placode (arrowheads). Late gastrula induction [Dex $(+)$ st. 12] results in less marked effects. Transversal sections show altered morphology of neural tube and confirm the diminished expression of neuronal genes (arrows). Probes used for ISH are indicated to the left of each row. $\boldsymbol{B}$, Lateral views of stage 37 embryo injected in one cell at the 2-cell stage with 500 pg of dnXREST and induced at late blastula stage. Note the defect of eye development in the injected side (bottom, arrow).

\section{XREST/NRSF is required for neuronal gene expression}

To understand the mechanisms underlying the apparent repression of neuronal genes produced by an impairment of XREST/NRSF function (Armisén et al., 2002) and taking into account the widespread expression of XREST/NRSF mRNA at early stages of development, we reexamined its role using a glucocorticoid-inducible (Kolm and Sive, 1995) dominantnegative XREST/NRSF construct (dnXREST). The dnXREST comprises the DNA binding domain of XREST, and it is devoid of the $\mathrm{N}$ and $\mathrm{C}$ domains known to recruit the corepressor proteins. Therefore, this truncated protein is expected to compete with the endogenous REST/NRSF for their target genes (Ballas et al., 2001).

Activation of this dominant-negative construct at stage 9 (late blastula), by exposure of the embryos to dexamethasone, resulted in a phenotype similar to that observed in external views of neural tube stage embryos expressing a constitutively active dnXREST (Armisén et al., 2002). Specifically, we found a decreased expression of NaV1.2, SCG10, and N-tubulin. In contrast, embryos not exposed to dexamethasone displayed normal expression patterns of neuronal genes in the primary nervous system (Fig. 1). Inspection of ISH sections of dexamethasone-induced embryos revealed an altered neural tube structure and gene expression patterns that are masked in anterodorsal whole-mount views by the overlying structures. The most prominent alterations included the distortion of the domain of $N$-tubulin-expressing cells in the neural tube and a partial decrease of its expression $(88 \% ; n=35)$, also observed with NaV1.2 staining (51\%; $n=45)$ and SCG10 (95\%; $n=$ 22). It is of interest that the expression of neuronal genes in the trigeminal placode, a territory that does not fold like the neural tube, was consistently diminished. We observed less marked effects in embryos in which dnXREST was induced at stage 12 (late gastrula) (70\% of distortion of N-tubulinexpressing domain, $n=20 ; 46 \%$ of alteration of $N a V 1.2$ pattern, $n=35 ; 49 \%$ of decrease of SCG10 expression, $n=35$ ) (Fig. 1A). To confirm these results, we have used a mechanistically independent approach to decrease XREST/NRSF function.
To that end, we blocked XREST/NRSF translation by injecting a $X R E S T / N R S F$-specific morpholino antisense oligonucleotide (MoXREST). The MoXREST-injected embryos displayed a similar phenotype to those injected with the dnXREST mRNA (Fig. 1A) (downregulation of tubulin 88\%, $n=33$; NaV1.2, 79\%, $n=$ 19; SCG10, 80\%, $n=20$ ). Embryos injected with dnXREST and exposed to dexamethasone at stage 9 showed lack of proper eye development at tail-bud stages (Fig. $1 B$ ). The sole exposure to dexamethasone at the equivalent stages or the injection of a control morpholino did not cause discernible changes in the expression of $N$-tubulin (supplemental Fig. S3, available at www. jneurosci.org as supplemental material).

\section{Interference of XREST/NRSF function disturbs neural patterning}

Because dnXREST promotes greater effects when is activated at late blastula than at late gastrula stages, REST/NRSF could affect neurogenesis at early stages, before terminal differentiation (Fig. 2). In Xenopus, at the neural plate stage, primary neurogenesis occurs in three rows of cells on each side of the midline. These neurogenic domains are marked by the expression of proneural and neurogenic genes, which promote neural determination and differentiation. The proneural gene neurogenin $(X-n g n r-1)$ promotes the expression of $X$-Delta-1 and the acquisition of neuronal fate (Ma et al., 1996). Conversely, it has been shown that, in the interspersed domains, the prepattern gene Zic2 inhibits neurogenesis (Brewster et al., 1998). We explored the effect of loss of REST/NRSF function on primary neurogenesis. We evaluated $N$-tubulin expression at this stage, because it is one of the earliest expressed genes in differentiated neurons (Chitnis et al., 1995). Induction of dnXREST at stage 9 clearly decreases the expression of $\mathrm{N}$ tubulin $(100 \% ; n=23)$. We also analyzed the expression of $\mathrm{NaV1.2}$, which is initially transcribed at later stages (Armisén et al., 2002). Interestingly, we found a premature and ectopic expression of this transcript at stage $14(52 \% ; n=58)$. Analysis of $X-n g n r-1$ and $X$-Delta- 1 expression reveals a marked decrease of these transcripts $(77 \%, n=62$; and $96 \%, n=24$, 


\section{dnXREST}

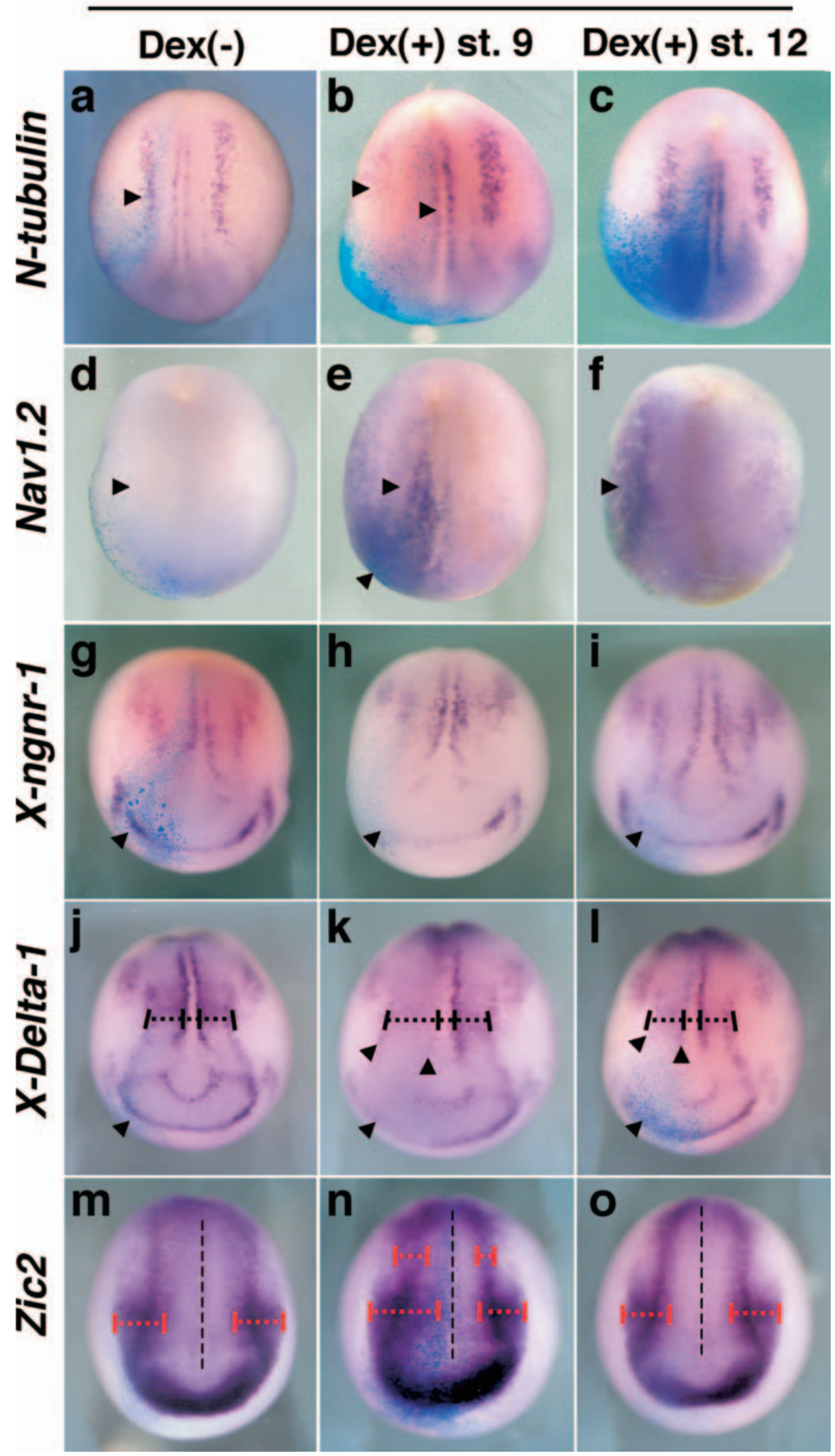

Figure 2. Loss of XREST/NRSF function disturbs neural patterning. Dorsal views of stage 15 embryos injected unilaterally with $500 \mathrm{pg}$ of $\mathrm{dnXREST}$. Anterior is down, and the injected side is to the left. The stage of dexamethasone addition is indicated on top and probes used for ISH are indicated to the left. Embryos induced at stage 9 [Dex(+) st. 9] displays inhibition of $\mathrm{N}$-tubulin, $X$-ngnr-1, and X-Delta-1 (arrowheads) and ventral displacement of neurogenic domains (brackets). Induction at stage 12 [DeX $(+)$ st. 12] results in subtler effects. In contrast, embryos induced at both stages exhibit a precocious and ectopic expression of NaV1.2 at stage 14 (arrowheads). Induction of dnXREST at stage 9 associates the expansion of non-neurogenic domain (brackets) marked by Zic2 and surrounded by X-Delta-1 (arrowheads). Activation of dnXREST at stage 12 did not result in the expansion of Zic2. respectively). Because the inhibition of neurogenesis could result from an increased activity of the Notch pathway (Chitnis et al., 1995), we evaluated the expression of Notc-1 and XHes-1, an effector of Notch signaling. We found that XHes- 1 transcript decreased $(90 \% ; n=$ 29), whereas Notch-1 expression pattern appear normal (supplemental Fig. S4, available at www.jneurosci.org as supplemental material). Conversely, the expression domain of Zic2 was strongly expanded in these dnXREST-injected embryos $(87 \% ; n=23)$. Induction of dnXREST at the end of gastrulation promoted similar, although subtler, effects in these genes ( $N$-tubulin, 30\%, $n=20$; NaV1.2, 40\%, $n=35 ; X-n g n r-1,40 \%$, $n=15 ; X$-Delta-1, 92\% light effect, $n=$ 13; and $Z i c 2,8 \%, n=12$ ). This could be the consequence of a decreased availability of the dominant-negative protein. However, Western blot analysis of Myc-tagged dnXREST protein reveals similar amounts of protein from blastula stages throughout neurulation (data not shown). These results indicate that XREST/NRSF function is required for proper patterning of the neuroectoderm during gastrulation.

\section{Inhibition of XREST/NRSF expands the neural plate and disturbs ectoderm patterning}

In addition to the reduced level of gene expression, we also consistently observed a ventral displacement of the lateral X-ngnr-1, X-Delta-1, and N-tubulin expression domains. This may be consequence of dnXREST affecting early neural specification. Therefore, we explored the effect of interference of XREST/NRSF function on the acquisition of the primary fates of the ectoderm, epidermis, neural crest, and neural plate, during gastrulation. First, we evaluated the loss of XREST/NRSF function in the expression of genes that are mediators of neural induction. Figure $3 A$ shows that induction of dnXREST at stage 9 promoted an expansion of the domain of ectodermal cells that express SoxD $(73 \% ; n=79)$, which is one of the earliest genes with neuralizing activity expressed in the prospective neuroectoderm (Mizuseki et al., 1998a). In addition, Sox $2(77 \% ; n=51)$, a factor involved in the maintenance of the neuroepithelial fate that is expressed later than SoxD in the neural plate (Mizuseki et al., 1998b), was also expanded. The analysis of Sox 2 expression at later stages revealed a persistent disruption of its normal pattern, including an expansion of the Sox2- 
A

dnXREST

Dex(-) Dex(+) st.9 Dex(+) st.12
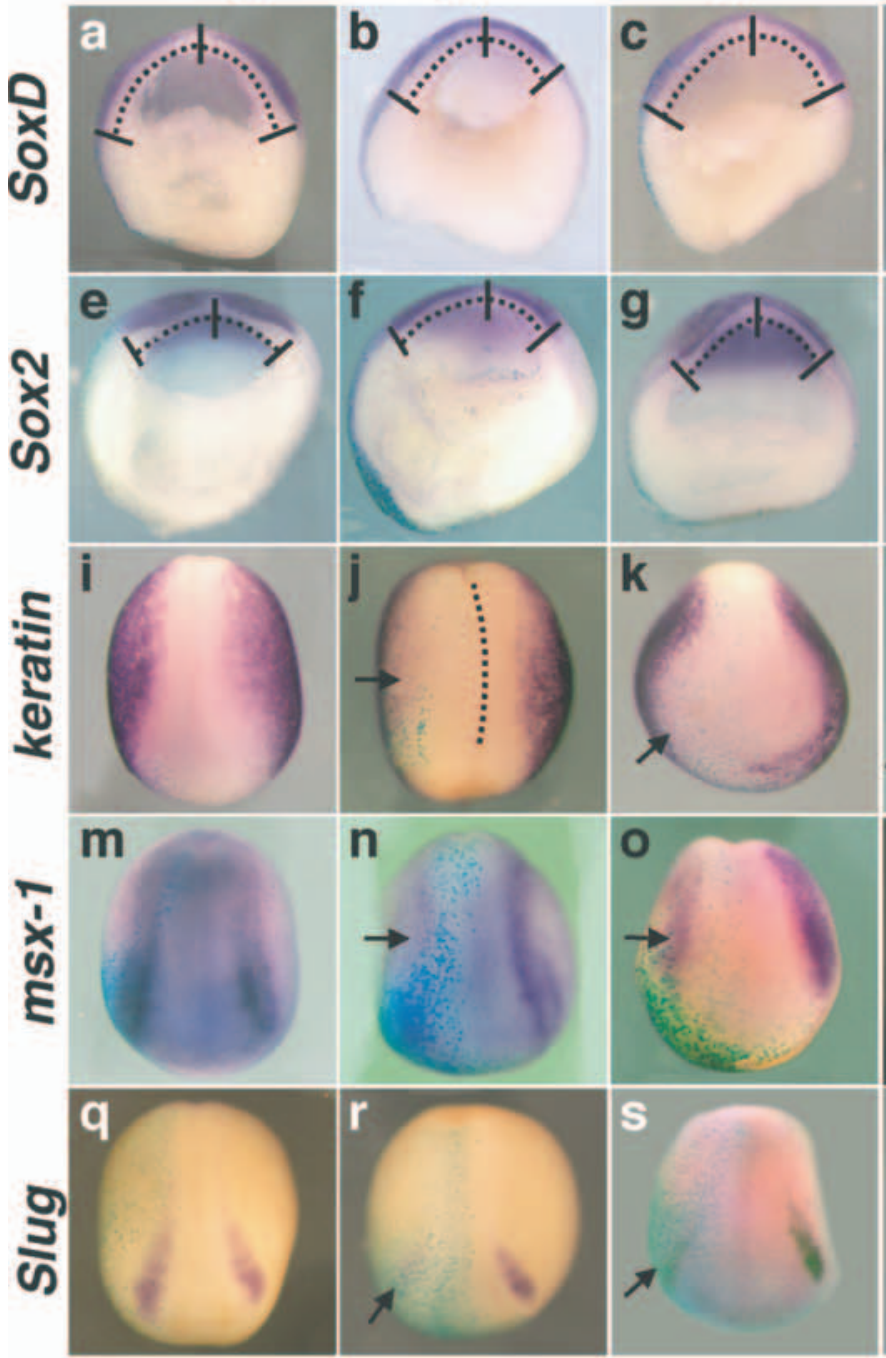

B

\section{dnXREST}

\section{$\operatorname{Dex}(-) \quad \operatorname{Dex}(+)$ st.9}
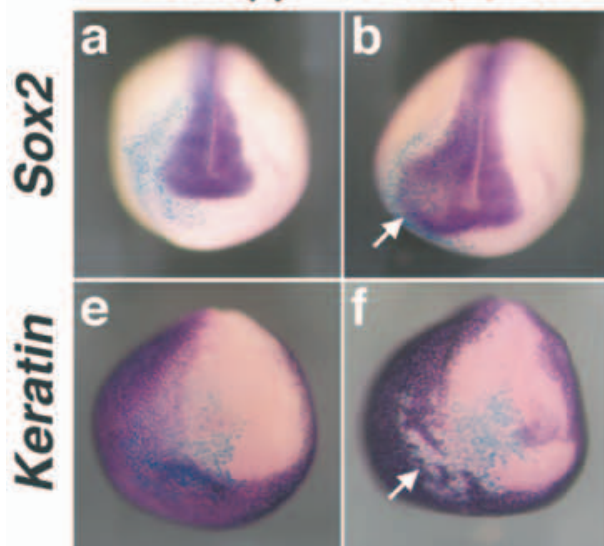

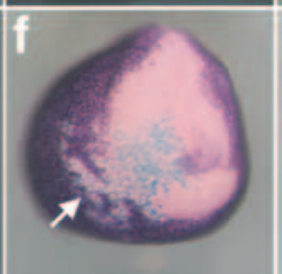

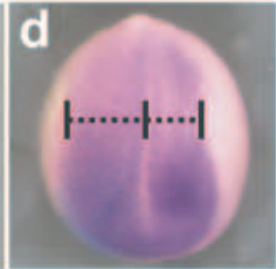
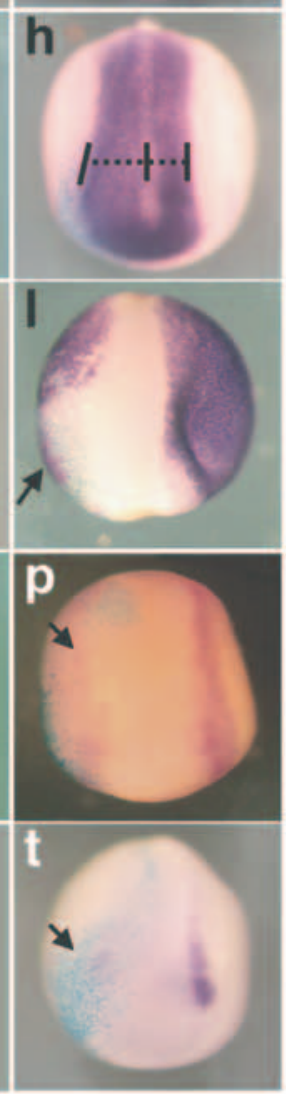

MoXREST

expressing tissue at the spinal territory and prospective eye field (supplemental Fig. S5, available at www.jneurosci.org as supplemental material). Conversely, the domain of expression of the epidermal keratin transcript was both laterally displaced and diminished $(71 \% ; n=52)$.

The displacement of the domains of expression of Sox 2 and keratin genes may reflect changes in the specification of the border of the neural plate. We therefore determined the effect of dnXREST on the expression domain of $m s x-1$, a gene directly regulated by the BMP4 signaling that promotes epidermal and neural crest fate and that is normally expressed in the early boundaries between neural and non-neural ectoderm (Suzuki et al., 1997). We also analyzed Slug, which is specifically expressed at the prospective neural crests and is activated downstream of $m s x-1$ in the genetic cascade that specifies this tissue (Mayor et al., 1995; Tríbulo et al., 2003). Induction of dnXREST at stage 9 resulted in a marked reduction of $m s x-1$ expression in the injected side as well as a ventral displacement of its expression domain $(90 \%$; $n=29)$. Similarly, expression of Slug was diminished and displaced toward ventral $(82 \% ; n=38)$. Embryos exposed to dexamethasone from late gastrula (stage 12) were affected to a lesser extent (SoxD, $42 \%, n=$ 36; Sox $2,57 \%, n=21$; keratin, $57 \%$, $n=21$; msx-1, 36\%, $n=44$; and Slug, $66 \%, n=29)$. Similar effects were found in embryos injected with the XREST/ NRSF-specific morpholino. We did not observe alterations of Sox 2 and Slug expression patterns in embryos injected with $\beta$-galactosidase and treated with dexamethasone or in embryos injected with a control morpholino (supplemental Fig. S3, available at www.jneurosci.org as
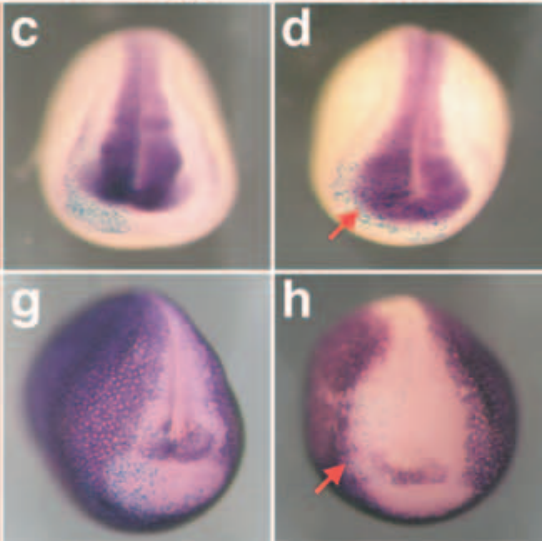

Figure 3. XREST/NRSF loss of function induces expansion of neural tissue. $\boldsymbol{A}$, Transversal sections $(\boldsymbol{a}-\boldsymbol{c}, \boldsymbol{e}-\boldsymbol{g})$, dorsal $(\boldsymbol{d}, \boldsymbol{h}-\boldsymbol{j}$, $\boldsymbol{m}-\boldsymbol{t})$ and anterior $(\boldsymbol{k}, \boldsymbol{I})$ views of neural plate stage embryos injected with $500 \mathrm{pg}$ of in vitro transcribed dnXREST mRNA or $5 \mathrm{pmol}$ of MOXREST (indicated on top). Probes used for ISH are indicated to the left of each row. Embryos injected with MoXREST or with
dnXREST and induced at late blastula [Dex(+)st. 9] exhibit expansion of the neural markers SoxD and Sox2 ( $\boldsymbol{a}-\boldsymbol{h}$, brackets) and a diminished expression of epidermal keratin $(\boldsymbol{j}, \boldsymbol{I}), m \mathrm{~ms}-1(\boldsymbol{n}, \boldsymbol{p})$, and Slug $(r, t)$ (arrows). Less severe effects are observed in embryos induced at late gastrula: $\operatorname{SoxD}(\boldsymbol{c})$, Sox2 $(\boldsymbol{g})$, keratin $(\boldsymbol{k}), \operatorname{msx}^{-1}(\boldsymbol{o})$ and Slug (s). Dex(+) st. 12, Embryos exposed to dexamethasone at stage 12. B, Anterior views of stage 18 embryos injected with 200 pg of dnXREST $(\boldsymbol{a}, \boldsymbol{b}, \boldsymbol{e}, \boldsymbol{f})$ or in combination with $1 \mathrm{ng}$ of XREST/ NRSF in one cell at the 2-cell stage $(\boldsymbol{c}, \boldsymbol{d}, \boldsymbol{g}, \boldsymbol{h})$ (indicated on top). Embryos injected with dnXREST induced at stage 9 exhibit enlargement of anterior neural plate, marked by Sox2 expression ( $\boldsymbol{b}$, arrows) and the lateral displacement and loss of keratin expression ( $\boldsymbol{f}$, ticeable defects $(\boldsymbol{c}, \boldsymbol{g})$. dnXREST/XREST embryos induced at stage 9 do not display an expanded domain of Sox 2 expression ( $\boldsymbol{d}$ ) and decreased keratin expression (arrows). arrows). Non-induced dnXREST/XREST embryos do not display no- 


\section{dnXREST

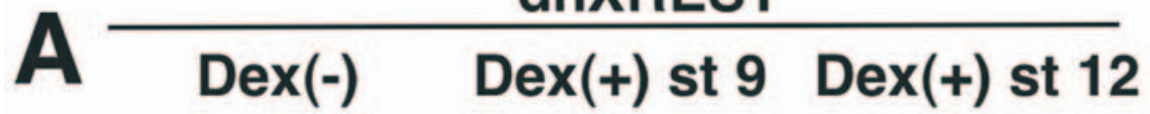

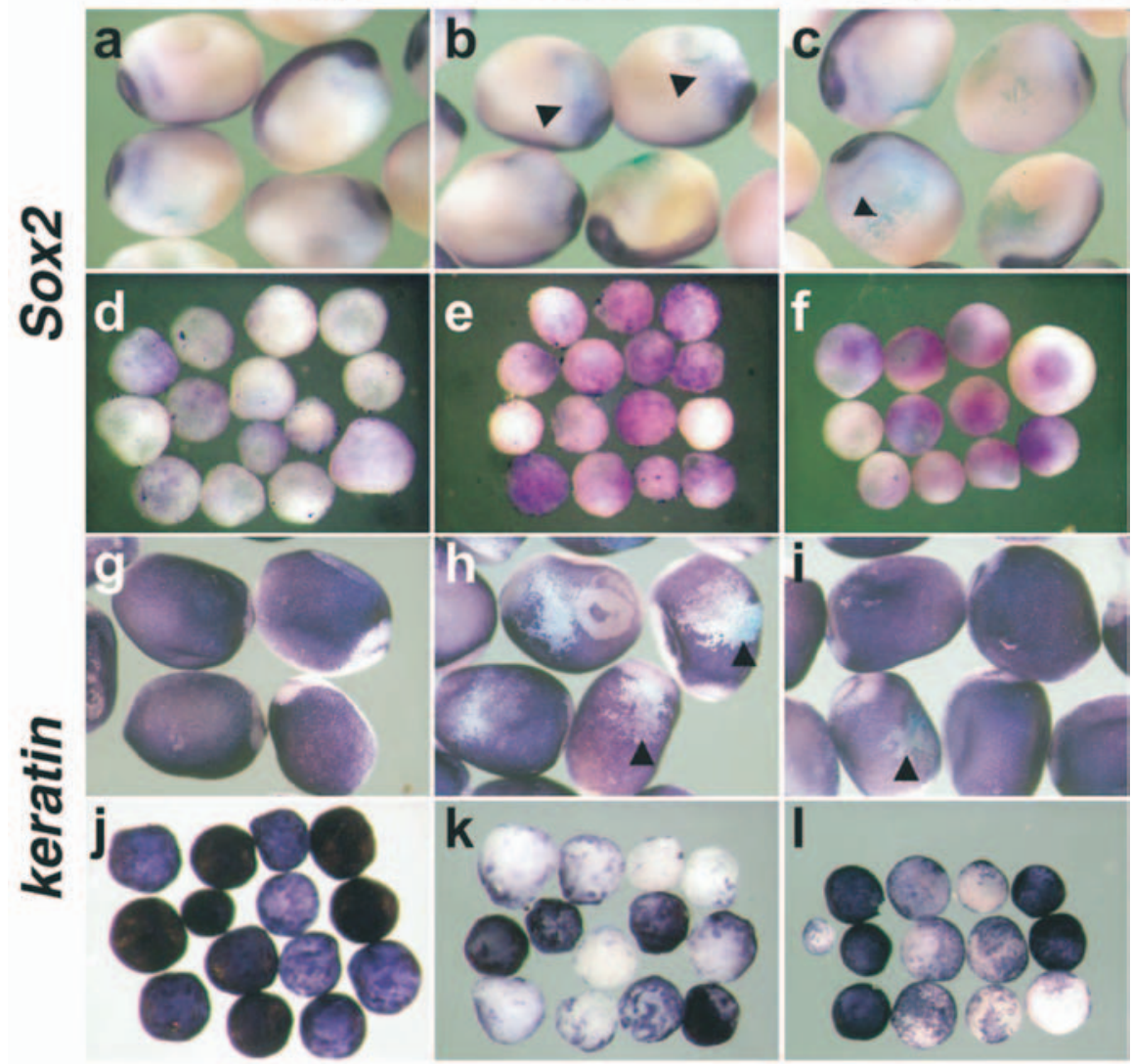

B

\section{dnXREST}

st. 11

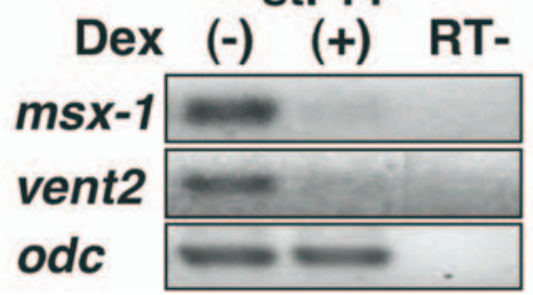

Figure 4. Decreased XREST/NRSF function inhibits the acquisition of epidermal fate and does not result in ectopic neural induction. $\boldsymbol{A}$, Lateral views of stage 16 embryos and animal ectoderm explants (animal caps) injected at the 8-cell stage in one of the most ventral animal blastomeres with $500 \mathrm{pg}$ of dnXREST $(\boldsymbol{a}-\boldsymbol{c}, \boldsymbol{g}-\boldsymbol{i})$ or in the four animal cells with GFP and $1 \mathrm{ng}$ of dnXREST $(\boldsymbol{d}-\boldsymbol{f}, \boldsymbol{j}-\boldsymbol{I})$. Animal caps were dissected at stage 9 and cultured until stage 16. Induction of dnXREST at stage 9 resulted in the increase of Sox 2 expression in animal caps $(\boldsymbol{e})$ but not in whole embryos $(\boldsymbol{b})$ and in the loss of keratin expression both in animal caps (arrowheads, $\boldsymbol{h}$ ) and whole embryos (arrowheads, $\boldsymbol{k}$ ). The activation of dnXREST at stage 12 results in subtler effects on Sox2 $(\boldsymbol{f})$ and keratin $(\boldsymbol{i}, \boldsymbol{I})$ expression. $\boldsymbol{B}, \mathrm{RT}-\mathrm{PCR}$ analysis of ectodermal explants (animal caps) from embryos injected animally with $1 \mathrm{ng}$ of dnXREST and either treated $(+)$ or untreated $(-)$ with dexamethasone (Dex) from stage 9 onward. Animal caps were collected at stage 10.5 (indicated on top) and analyzed for expression of the indicated RNAs.

supplemental material). The effects of dnXREST were specific because the coinjection of equimolar quantities of dnXREST RNA and the RNA encoding the full-length XREST/NRSF protein reversed the defects on the specification of ectodermal domains caused by dnXREST alone (Sox2, 50\%, $n=24$; keratin, $51 \%, n=20$ ) (Fig. 3B). Furthermore, the effects of the morpholino antisense oligonucleotide were partly rescued by the coinjec- tion of the RNA encoding ZREST/NRSF $(64 \%$; $n=28)$; this control was used because the morpholino oligonucleotide is complementary to the coding sequence of XREST/NRSF RNA (supplemental Fig. S6, available at www.jneurosci.org as supplemental material).

Because the observed defects on dorsoventral patterning of the ectoderm could be ascribed to perturbations in the specification of the underlying mesoderm, we examined the effect of dnXREST overexpression on two mesoderm markers, chordin and MyoD. Chordin is expressed in the dorsal mesoderm at early gastrula stages and later in axial mesoderm (Sasai et al., 1994), whereas the muscle determination gene $\mathrm{MyoD}$ is expressed in the paraxial mesoderm (Hopwood and Gurdon, 1990). However, we did not find consistent perturbations in the expression patterns of these two genes (chordin, $n=$ 59; MyoD, $n=28$; data not shown). The expansion of the neuroectoderm could also be the result of increased proliferation of this cell population. To evaluate the latter possibility, we assessed the rate of proliferation by staining the dnXRESTinjected embryos with an antiphosphohistone-H3 antibody. We did not observe differences in the number of dividing cells between injected and noninjected embryos or between the injected and non-injected sides of the same embryo (data not shown). Thus, neither defects in mesoderm patterning nor neuroectoderm proliferation account for our results.

\section{XREST1 overexpression does not affect neural development}

Two REST/NRSF splice variants have been described in Xenopus (R. Armisén and M. Kukuljan, unpublished data), a "full length" that comprises the eight zinc finger DNA binding motif and corepressor domains at $\mathrm{N}$ - and $\mathrm{C}$-terminal position, and a truncated variant that comprises the $\mathrm{N}$-terminal domain and the first four zinc fingers, which is analogous to rat REST1 (Palm et al., 1998). It was shown that truncated forms of REST/NRSF might act as dominant negatives of REST function in PC12 cells and in small-cell lung cancer (Shimojo et al., 1999; Coulson et al., 2000). The expression of this form (XREST1), assessed by reverse transcription (RT)-PCR with primers designed on the basis of its specific $3^{\prime}$ untranslated region, is not detectable before midgastrula (Armisén and Kukuljan, unpublished data), in contrast with the continuous expression of XREST/NRSF as a maternal and zygotic transcript (Armisén et al., 2002). To study whether XREST1 modulates the endogenous XREST/NRSF function, we injected synthetic RNA coding for XREST1 and did not find alterations in 
the expression patterns of neuronal, neural, and neural crest markers (supplemental Fig. S3, available at www.jneurosci.org as supplemental material). A selective impairment of one of these splice variants of REST/NRSF is not feasible, because they share the sequence targeted by the Mo-XREST and both bind to RE-1 (M. E. Cabrejos and M. Kukuljan, unpublished results), which is also the binding site for the dominant-negative construction.

\section{Interference of XREST/NRSF mimics the decrease of BMP signaling in the ectoderm}

To explore the role of XREST/NRSF in the acquisition of epidermal or neural fates by the ectoderm, beyond the determination of the boundaries between neural and non-neural domains, we looked at the cell fate of ventral ectoderm at which dnXREST RNA had been targeted. We also examined the expression of marker genes in isolated ectoderm explants (animal caps) obtained from late blastula dnXREST-injected embryos. As shown in Figure $4 A$, ventral expression of dnXREST does not associate with a significant ectopic expression of Sox2. This observation correlates with a weak acquisition of the neural fate, measured as the expression of the same transcript in animal caps. Conversely, expression and induction of dnXREST lead to a marked loss of the expression of keratin in ventral territories, as well as in the ectodermal ex-

plants (Fig. $4 A$ ). It is well established that the activity of the BMP signaling cascade is required for the specification of the epidermis (Wilson and Hemmati-Brivanlou, 1995), whereas a decreased level of this signal is a requisite for the acquisition of the neural fate (for review, see De Robertis and Kuroda, 2004), although additional signals, such as those leading to activation of the cascade of mitogen-activated protein kinases, appear to be required (Linker and Stern, 2004; Delaune et al., 2005; Kuroda et al., 2005). According to the wealth of information regarding the roles of BMPs in ectodermal patterning, the interference of XREST/ NRSF function described above mimics the effects of decreasing BMP signaling. A possible explanation for this observation is that REST/NRSF function affects this pathway. The binding of the BMP family molecules to their receptors activates the transcription of a variety of genes in diverse cell types. Therefore, the interference of BMP signaling by dnXREST should result in a decrease of the expression of genes regulated by BMP. We compared the relative abundance of transcripts from two genes regulated by BMP, Vent- 2 and $m s x-1$, in stage 10.5 ectodermal explants obtained from dnXREST-injected embryos, exposed or not to dexamethasone at the equivalent of stage 9.5. We found that induction of dnXREST associates with the decrease of Vent-2 and $m s x-1$ (Fig. $4 B$ ). Additionally, we tested the possibility that dnXREST antagonizes the effect of overexpression of Bmp4 on the acquisition of ectodermal cell fates. Induction of dnXREST restores the size of the neural plate $(73 \% ; n=37)$, which is decreased by the sole overexpression of Bmp4 (Fig. 5). Similarly,

\section{AnXREST}
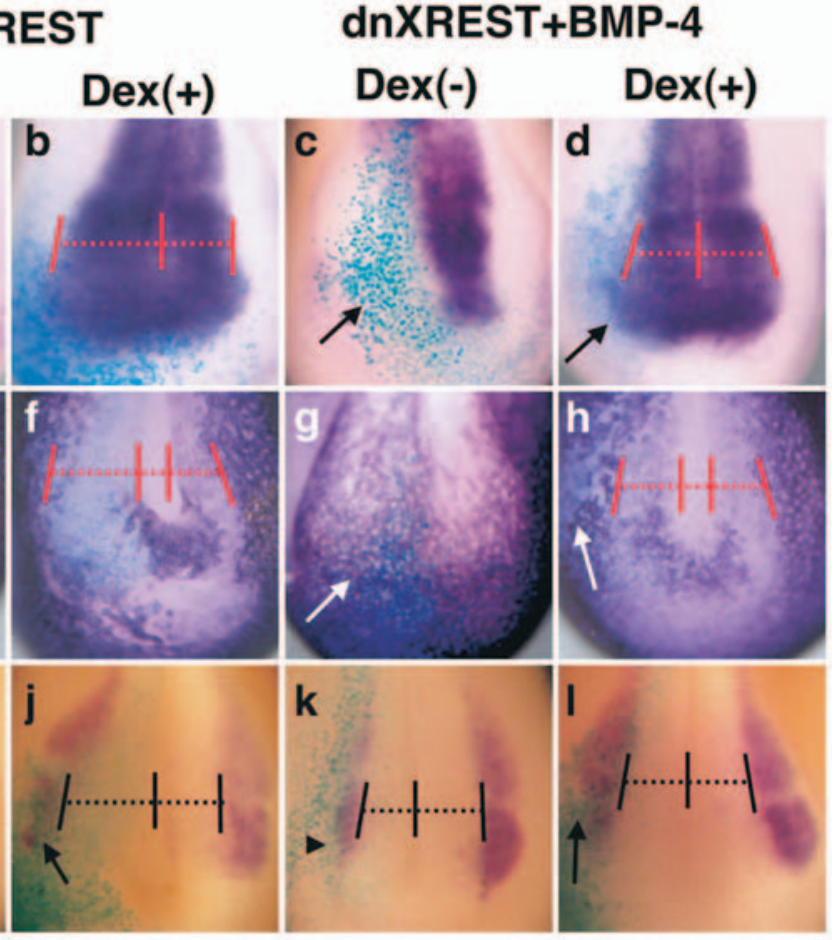
f
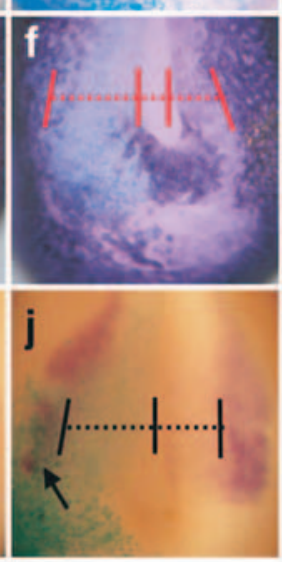

Figure 5. XREST loss of function reverts the effect of Bmp4 misexpression on ectodermal patterning. Anterior views of stage 18

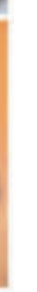
embryos injected with $500 \mathrm{pg}$ of dnXREST, alone or in combination with $500 \mathrm{pg}$ of $B \mathrm{mp} 4 \mathrm{mRNA}$ (indicated on top). Probes used for ISH are indicated to the left of each row, and the stage of dexamethasone addition is indicated on top. The injected side of not induced dnXREST/BMP4 embryos exhibits the loss or decrease of neural ectoderm revealed by the domain of Sox2 expression ( $c$ keratin $(\boldsymbol{h})$, and Slug $(\boldsymbol{I})$ in relation to the neural plate size (brackets). Nevertheless, loss of keratin $(\boldsymbol{f})$ and Slug $(\boldsymbol{j})$ expression observed in dnXREST-injected embryos induced at stage 9 was not efficiently rescued by the BMP4 coexpression ( $\boldsymbol{h}, \boldsymbol{l}$, arrows).

dnXREST reverses the dorsal expansion in the domain of keratin expression $(87 \% ; n=37)$ and the dorsal displacement of Slug expression domain $(70 \% ; n=10)$ that result from $B m p 4$ overexpression (Fig. 5).

\section{Discussion}

The study of the function of REST/NRSF, originally viewed as a master regulator of neuronal gene expression, continues to reveal complex mechanisms. Recent analyses indicate that the association of REST/NRSF with target genes during neural development varies as neuronal differentiation progresses (Ballas et al., 2005; Sun et al., 2005). It is apparent that the role of REST/ NRSF and associated complexes is relevant for the transitions that determine the passage from the undifferentiated precursor stage to neural progenitor and differentiated neuron. The findings reported here provide in vivo evidence for a role of REST/ NRSF in the early development of the Xenopus nervous system, in which it is required for the correct patterning of the ectoderm. This involves the correct specification of the neuroepithelial domain and adequate development of the non-neural ectoderm.

The earliest developmental defects associated with the impairment of REST/NRSF function in Xenopus consist of an expansion of the neural plate, ventral displacement of neural crest markers, and patchy loss of keratin. One possible explanation for our observations is that impairment of XREST/NRSF decreases BMP signaling in the ectoderm. An expansion of the neural plate, with concomitant decrease of the prospective epidermis and the ventral expansion of the neural crest, occurs when BMP signaling is 
decreased (LaBonne and Bronner-Fraser, 1998). Also the normal specification of the neural crest requires a critical level of BMP signaling (Tríbulo et al., 2003). Furthermore, the expression of epidermal keratin requires activation of the BMP pathway (Wilson and Hemmati-Brivanlou, 1995). Additionally, the induction of dnXREST leads to displacement of the primary neurogenic domains, in a manner similar to that observed when BMP signaling is reduced in Xenopus (Wawersik et al., 2005). We found that the induction of dnXREST leads to a decrease in the amount of mRNAs of genes activated by BMP in the ectoderm, Vent 2 and $m s x-1$. Moreover, the interference of XREST/NRSF function rescues the effect of Bmp4 overexpression on the size of the neural plate. The loss of epidermal character in the ventral ectoderm is not accompanied by its neuralization. This could be attributable to the requirement of additional signals. Indeed, the combined action of BMP antagonists and FGF signaling is essential to generate neural tissue (Linker and Stern, 2004; Delaune et al., 2005; Kuroda et al., 2005).

Although the impairment of REST/NRSF function phenocopies features observed when the BMP signal is diminished and it is rescued by the overexpression of BMP4, it must be emphasized that alternative or complementary mechanisms should be considered and explored. Thus, it is possible that a decrease of REST/NRSF function impairs the ability of ectodermal cells to acquire specific fates in response to BMP instead of affecting the BMP signaling itself. Because ventral cells are also a source of BMP, a failure in their proper differentiation will further reduce the BMP levels and signaling. Thus, the observed ventralization would be a consequence of a more fundamental defect in the acquisition of cell fates. An unbiased search and functional validation of genes that are regulated by REST/ NRSF in the ectoderm during gastrulation is required to ascertain the mechanisms by which this repressor contributes to the patterning of the ectoderm.

The decreased expression of neuronal genes (NaV1.2, N-tubulin, and SCG10) caused by the impairment of XREST/NRSF function appears to be secondary to disruption of ectodermal patterning. Because the mechanisms that link neural induction and neurogenesis are still poorly understood, the basis of the phenotype observed when XREST/NRSF function is decreased remains essentially unknown. We found that decreased XREST/NRSF function leads to a decreased expression of the proneural gene X-ngnr-1 (Ma et al., 1996) and the neurogenic gene X-Delta-1 (Chitnis et al., 1995). A mechanism possibly leading to this phenotype is an increase in the function of the Notch pathway (Chitnis and Kintner, 1996), which could be brought about by dnXREST-mediated derepression; however, we found an apparently normal expression of Notch-1 and a decreased expression of its effector XHes-1. These results do not support the mechanism stated above. Conversely, we observed the expansion of the expression domain of $\mathrm{Zic} 2$, an antineurogenic gene (Brewster et al., 1998). Therefore, the increased expression of Zic2 may contribute to the disruption of neurogenesis observed when the function of REST/NRSF is impaired. The increase in Zic2 may be the indirect result of the wide perturbation of ectodermal patterning or may arise from a more direct regulatory effect of REST/NRSF. We cannot discard a more profound defect in the ability of ectodermal cells to commit to their normal fates, because we observe impaired neurogenesis, loss of neural crest markers, and loss of keratin expression. This inability of the ectoderm to differentiate in vivo when REST/NRSF function is decreased may be a correlate of the recently reported requirement of REST/NRSF function in pluripotent cells to transit to neural progenitors and mature neurons in vitro (Ballas et al., 2005).

We observed that induction of the dnXREST associates with derepression of NaV1.2 in vivo; this is consistent with the role of REST/NRSF as a repressor. The premature and ectopic expression of $\mathrm{NaV1.2}$ may not be directly related to the abnormal patterning of the ectoderm and may result from the direct derepression of this gene in ectodermal cells, as described in rat fibroblasts (Lunyak et al., 2002). However, this ectopic expression is transient, and it was not observed for N-tubulin or SCG10, which supports the occurrence of additional gene-, cell type-, and stage-specific regulatory mechanisms on the expression of neuronal genes.

It is known that REST/NRSF recruits complexes with chromatinremodeling activity. Because numerous components of these complexes have been identified, it will be of interest to understand the molecular mechanisms associated with the REST/NRSF activity during development. Our results are coincident with the report of the association between loss of Brgl function, a component of the mating switching/sucrose nonfermenting (SWI/SNF) complex, and the expansion of the neural plate and later alterations of neural development (Seo et al., 2005). REST/NRSF interacts with components of the SWI/SNF complex (Battaglioli et al., 2002), and it is thought to contribute to impose variable degrees of repression around RE-1 or other REST/NRSF binding sites. Therefore, the described phenotypes may arise from common perturbation of these chromatin-remodeling complexes. Nevertheless, and because all of these molecules, including CoREST (Andrés et al., 1999), can also form complexes independent of REST/NRSF, the analysis of the functions of each of these constituents goes beyond the scope of our current study of the role of REST/NRSF in early development.

Despite the high number of genes potentially regulated by REST/NRSF, the loss of its function results in defined ectodermal defects and not in catastrophic massive activation of transcription. The increased sensitivity of some cell types or processes to a decrease in REST/NRSF function may result from the restricted expression of components of repressor complexes and of specific activators. Thus, not all genes that are potentially targets of REST/ NRSF-mediated repression are ubiquitously and continuously transcribed when REST/NRSF function is lost, which is also apparent by studying the effect of REST/NRSF deletion in the mouse (Chen et al., 1998). It must be noticed that our study focused on ectodermal patterning to account for defects in neurogenesis, which were the most obvious effects of decreased REST/NRSF function. A close scrutiny of other processes may reveal additional developmental roles of REST/NRSF in vivo.

REST/NRSF protein degradation in stem cells is dramatically triggered by retinoic acid (RA) (Ballas et al., 2005). Thus, REST/ NRSF may provide a link between RA- and BMP-activated signals. Conversely, it has been reported that REST/NRSF may be subject to transcriptional regulation by the Wnt canonical pathway (Willert et al., 2002; Nishihara el al., 2003). Furthermore, the REST/NRSF corepressor CoREST was identified in Xenopus as a Xiro1-regulated gene (de la Calle-Mustienes et al., 2002), thus providing another link between Wnt signaling and REST/NRSF function. These observations are compatible with a role of REST/NRSF as an integrator of signals imposed by overlapping diffusible morphogens.

Our results are in line with the reported expression patterns of REST/NRSF in neuronal precursors and the recent communication of an REST/NRSF-mediated control of gene expression of neural stem cells (Kuwabara et al., 2004; Ballas et al., 2005; Sun et al., 2005). Thus, the in vivo physiological role of REST/NRSF goes beyond the repression of neuronal genes expression in non-neural cells and neural progenitors and appears to extend to the regulation of the progression from the stage of neuroectoderm toward neurogenesis and also to the modulation of the early ectodermal patterning. 


\section{References}

Andrés ME, Burger C, Peral-Rubio MJ, Battaglioli E, Anderson ME, Grimes J, Dallman J, Ballas N, Mandel G (1999) CoREST: a functional corepressor required for regulation of neural-specific gene expression. Proc Natl Acad Sci USA 96:9873-9878.

Armisén R, Fuentes R, Olguín P, Cabrejos ME, Kukuljan M (2002) Repressor element-1 silencing transcription/neuron-restrictive silencer factor is required for neural sodium channel expression during development of Xenopus. J Neurosci 22:8347-8351.

Ballas N, Battaglioli E, Atouf F, Andrés ME, Chenoweth J, Anderson ME, Burger C, Moniwa M, Davie JR, Bowers WJ, Federoff HJ, Rose DW, Rosenfeld MG, Brehm P, Mandel G (2001) Regulation of neuronal traits by a novel transcriptional complex. Neuron 31:353-365.

Ballas N, Grunseich C, Lu DD, Speh JC, Mandel G (2005) REST and its corepressors mediate plasticity of neuronal gene chromatin throughout neurogenesis. Cell 121:645-657.

Battaglioli E, Andrés ME, Rose DW, Chenoweth JG, Rosenfeld MG, Anderson ME, Mandel G (2002) REST repression of neuronal genes requires components of the hSWI.SNF complex. J Biol Chem 277:41038-41045.

Brewster R, Lee J, Ruiz i Altaba A (1998) Gli/Zic factors pattern the neural plate by defining domains of cell differentiation. Nature 393:579-583.

Bruce AW, Donaldson IJ, Wood IC, Yerbury SA, Sadowski MI, Chapman M, Gottgens B, Buckley NJ (2004) Genome-wide analysis of repressor element 1 silencing transcription factor/neuron-restrictive silencing factor (REST/NRSF) target genes. Proc Natl Acad Sci USA 101:10458-10463.

Chen ZF, Paquette AJ, Anderson DJ (1998) NRSF/REST is required in vivo for repression of multiple neuronal target genes during embryogenesis. Nat Genet 20:136-142.

Chitnis A, Kintner C (1996) Sensitivity of proneural genes to lateral inhibition affects the pattern of primary neurons in Xenopus embryos. Development 122:2295-2301.

Chitnis A, Henrique D, Lewis J, Ish-Horowicz D, Kintner C (1995) Primary neurogenesis in Xenopus embryos regulated by a homologue of the Drosophila neurogenic gene Delta. Nature 375:761-766.

Chong JA, Tapia-Ramirez J, Kim S, Toledo-Aral JJ, Zheng Y, Boutros MC, Altshuller YM, Frohman MA, Kraner SD, Mandel G (1995) REST: a mammalian silencer protein that restricts sodium channel gene expression to neurons. Cell 80:949-957.

Coulson JM, Edgson JL, Woll PJ, Quinn JP (2000) A splice variant of the neuron-restrictive silencer factor repressor is expressed in small cell lung cancer: a potential role in derepression of neuroendocrine genes and a useful clinical marker. Cancer Res 60:1840-1844.

de la Calle-Mustienes E, Modolell J, Gómez-Skármeta JL (2002) The Xirorepressed gene CoREST is expressed in Xenopus neural territories. Mech Dev 110:209-211.

Delaune E, Lemaire P, Kodjabachian L (2005) Neural induction in Xenopus requires early FGF signalling in addition to BMP inhibition. Development 132:299-310.

De Robertis EM, Kuroda H (2004) Dorsal-ventral patterning and neural induction in Xenopus embryos. Annu Rev Cell Dev Biol 20:285-308.

Gawantka V, Delius H, Hirschfeld K, Blumenstock C, Niehrs C (1995) Antagonizing the Spemann organizer: role of the homeobox gene Xvent-1. EMBO J 14:6268-6279.

Gómez-Skármeta J, de La Calle-Mustienes E, Modolell J (2001) The Wntactivated Xiro1 gene encodes a repressor that is essential for neural development and downregulates Bmp4. Development 128:551-560.

Grimes JA, Nielsen SJ, Battaglioli E, Miska EA, Speh JC, Berry DL, Atouf F, Holdener BC, Mandel G, Kouzarides T (2000) The co-repressor $\mathrm{mSin} 3 \mathrm{~A}$ is a functional component of the REST-CoREST repressor complex. J Biol Chem 275:9461-9467.

Harland RM (1991) In situ hybridization: an improved whole-mount method for Xenopus embryos. Methods Cell Biol 36:685-695.

Hopwood ND, Gurdon JB (1990) Activation of muscle genes without myogenesis by ectopic expression of MyoD in frog embryo cells. Nature 347:197-200

Huang Y, Myers SJ, Dingledine R (1999) Transcriptional repression by REST: recruitment of Sin3A and histone deacetylase to neuronal genes. Nat Neurosci 2:867-872.

Jonas E, Sargent TD, Dawid IB (1985) Epidermal keratin gene expressed in embryos of Xenopus laevis. Proc Natl Acad Sci USA 82:5413-5417.

Kolm PJ, Sive HL (1995) Efficient hormone-inducible protein function in Xenopus laevis. Dev Biol 171:267-272.
Kraner SD, Chong JA, Tsay HJ, Mandel G (1992) Silencing the type II sodium channel gene: a model for neural-specific gene regulation. Neuron 9:37-44.

Kuroda H, Fuentealba L, Ikeda A, Reversade B, De Robertis EM (2005) Default neural induction: neuralization of dissociated Xenopus cells is mediated by Ras/MAPK activation. Genes Dev 19:1022-1027.

Kuwabara T, Hsieh J, Nakashima K, Taira K, Gage FH (2004) A small modulatory dsRNA specifies the fate of adult neural stem cells. Cell 116:779-793.

Kuwahara K, Saito Y, Takano M, Arai Y, Yasuno S, Nakagawa Y, Takahashi N, Adachi Y, Takemura G, Horie M, Miyamoto Y, Morisaki T, Kuratomi S, Noma A, Fujiwara H, Yoshimasa Y, Kinoshita H, Kawakami R, Kishimoto I, Nakanishi M, et al. (2003) NRSF regulates the fetal cardiac gene program and maintains normal cardiac structure and function. EMBO J 22:6310-6321.

La Bonne C, Bronner-Fraser M (1998) Neural crest induction in Xenopus: evidence for a two-signal model. Development 125:2403-2414.

Linker C, Stern CD (2004) Neural induction requires BMP inhibition only as a late step, and involves signals other than FGF and Wnt antagonists. Development 131:5671-5681.

Lunyak VV, Burgess R, Prefontaine GG, Nelson C, Sze SH, Chenoweth J, Schwartz P, Pevzner PA, Glass C, Mandel G, Rosenfeld MG (2002) Corepressor-dependent silencing of chromosomal regions encoding neuronal genes. Science 298:1747-1752.

Ma Q, Kintner C, Anderson DJ (1996) Identification of neurogenin, a vertebrate neuronal determination gene. Cell 87:43-52.

Mayor R, Morgan R, Sargent MG (1995) Induction of the prospective neural crest of Xenopus. Development 121:767-777.

Mizuseki K, Kishi M, Shiota K, Nakanishi S, Sasai Y (1998a) SoxD: an essential mediator of induction of anterior neural tissues in Xenopus embryos. Neuron 21:77-85.

Mizuseki K, Kishi M, Matsui M, Nakanishi S, Sasai Y (1998b) Xenopus Zicrelated-1 and Sox-2, two factors induced by chordin, have distinct activities in the initiation of neural induction. Development 125:579-587.

Mori N, Schoenherr C, Vandenbergh DJ, Anderson DJ (1992) A common silencer element in the SCG10 and type II $\mathrm{Na}^{+}$channel genes binds a factor present in nonneuronal cells but not in neuronal cells. Neuron 9:45-54.

Niewkoop PD, Faber J (1967) Normal table of Xenopus laevis Daudin. Amsterdam: North-Holland.

Palm K, Belluardo N, Metsis M, Timmusk T (1998) Neuronal expression of zinc finger transcription factor REST/NRSF/XBR gene. J Neurosci 18 $1280-1296$

Paquette AJ, Perez SE, Anderson DJ (2000) Constitutive expression of the neuron-restrictive silencer factor (NRSF)/REST in differentiating neurons disrupts neuronal gene expression and causes axon pathfinding errors in vivo. Proc Natl Acad Sci USA 97:12318-12323.

Roopra A, Qazi R, Schoenike B, Daley TJ, Morrison JF (2004) Localized domains of G9a-mediated histone methylation are required for silencing of neuronal genes. Mol Cell 14:727-738.

Sasai Y, Lu B, Steinbeisser H, Geissert D, Gont LK, De Robertis EM (1994) Xenopus chordin: a novel dorsalizing factor activated by organizerspecific homeobox genes. Cell 79:779-790.

Schoenherr CJ, Anderson DJ (1995) The neuron-restrictive silencer factor (NRSF): a coordinate repressor of multiple neuron-specific genes. Science 267:1360-1363.

Schoenherr CJ, Paquette AJ, Anderson DJ (1996) Identification of potential target genes for the neuron-restrictive silencer factor. Proc Natl Acad Sci USA 93:9881-9886.

Seo S, Richardson GA, Kroll KL (2005) The SWI/SNF chromatin remodeling protein $\mathrm{Brg} 1$ is required for vertebrate neurogenesis and mediates transactivation of Ngn and NeuroD. Development 132:105-115.

Shimojo M, Paquette AJ, Anderson DJ, Hersh LB (1999) Protein kinase A regulates cholinergic gene expression in PC12 cells: REST4 silences the silencing activity of neuron-restrictive silencer factor/REST. Mol Cell Biol 19:6788-6795.

Sive HL, Grainger RM, Harland RM (2000) Early development of Xenopus laevis. A laboratory manual. Cold Spring Harbor, NY: Cold Spring Harbor Laboratory.

Sun YM, Greenway DJ, Johnson R, Street M, Belyaev ND, Deuchars J, Bee T, Wilde S, Buckley NJ (2005) Distinct profiles of REST interactions with its target genes at different stages of neuronal development. Mol Biol Cell $16: 5630-5638$ 
Suzuki A, Ueno N, Hemmati-Brivanlou A (1997) Xenopus msx1 mediates epidermal induction and neural inhibition by BMP4. Development 124:3037-3044.

Tríbulo C, Aybar MJ, Nguyen VH, Mullins MC, Mayor R (2003) Regulation of Msx genes by a Bmp gradient is essential for neural crest specification. Development 130:6441-6452.

Turner DL, Weintraub H (1994) Expression of achaete-scute homolog 3 in Xenopus embryos converts ectodermal cells to a neural fate. Genes Dev 8:1434-1447.

Wawersik S, Evola C, Whitman M (2005) Conditional BMP inhibition in Xenopus reveals stage-specific roles for BMPs in neural and neural crest induction. Dev Biol 277:425-442.
Westbrook TF, Martin ES, Schlabach MR, Leng Y, Liang AC, Feng B, Zhao JJ, Roberts TM, Mandel G, Hannon GJ, Depinho RA, Chin L, Elledge SJ (2005) A genetic screen for candidate tumor suppressors identifies REST. Cell 121:837-848.

Willert J, Epping M, Pollack JR, Brown PO, Nusse R (2002) A transcriptional response to Wnt protein in human embryonic carcinoma cells. BMC Dev Biol 2:8.

Wilson PA, Hemmati-Brivanlou A (1995) Induction of epidermis and inhibition of neural fate by Bmp-4. Nature 376:331-333.

Yeo M, Lee SK, Lee B, Ruiz EC, Pfaff SL, Gill GN (2005) Small CTD phosphatases function in silencing neuronal gene expression. Science 307: 596-600. 